\title{
2D Geo-Electrical Imaging for Groundwater Exploration in Shika, along Zaria-Funtua Road North of Ahmadu Bello University Main Campus, Samaru, Zaria
}

\author{
${ }^{* 1}$ INICHINBIA, S; ${ }^{2}$ SULE, PO \\ ${ }^{*}$ Department of Physics, University of Port Harcourt, Port Harcourt, Nigeria. \\ ${ }^{2}$ Department of Physics, Ahmadu Bello University, Zaria, Nigeria \\ *Corresponding author Email: Sonny.inichinbia@yahoo.com
}

\begin{abstract}
A two dimensional (2D) geoelectrical tomography of Ahmadu Bello University Teaching Hospital Premises was carried out with the aim of identifying a suitable location for siting a borehole. This was sequel to the fact that a borehole drilled without proper geophysical investigation in the quarters for resident doctors did not produce water. State-of-the-art equipment was employed and 2D surveying proved a powerful geological mapping tool, for use in hydrogeological mapping including engineering and environmental applications. The $2 \mathrm{D}$ inversion results of the survey were correlated with the lithology information obtained from the boreholes in Jama'a village, and the hostels and the residential quarters of ABUTH. The stratigraphic structure of the study area is very complex and is a product of volcanic and magmatic activities of various ages. Based on the geo-electrical images obtained in the study area, three distinct layers were revealed, the overburden with an average thickness of about $16 \mathrm{~m}-26 \mathrm{~m}$. The overburden is immediately underlain by the weathered basement, $5 \mathrm{~m}-14 \mathrm{~m}$ thick which consists of disintegrated schistose rock materials, sand and gravel. This layer has a relatively low resistivity due to the presence of water and clay, which reduces the permeability, so this layer is thus regarded as the aquifer. The fresh basement rock was encountered at a variable depth of between $21 \mathrm{~m}$ and $>30 \mathrm{~m}$ with resistivity $1223 \Omega \mathrm{m}$ up to $11918 \Omega \mathrm{m}$. These results agree with the borehole logs. The complete set of borehole logs used in this research were obtained from the original hydro-geologic assessment report of the groundwater research department of the National Water Resources Institute (NWRI), Mando, Kaduna; Kaduna State, Nigeria.
\end{abstract}

DOI: https://dx.doi.org/10.4314/jasem.v22i4.30

Copyright: Copyright (c) 2018 Inichinbia and Sule. This is an open access article distributed under the Creative Commons Attribution License (CCL), which permits unrestricted use, distribution, and reproduction in any medium, provided the original work is properly cited.

Dates: Received: 10 January 2018; Revised: 18 February: 2018; Accepted: 22 March 2018

\section{Keywords: Tomography, Inversion, Lithology, Geo-electrical, Aquifer, Borehole}

Hydrogeological studies are increasingly demanding more precise and more detailed geo-electrical information at shallow depth. In order to make this cost effective and to compete with shallow, relatively inexpensive drilling, optimal use is made of digital techniques, both in the acquisition and processing of field data. Electrical Resistivity Imaging (ERI) technique had been applied for borehole siting in hard rock (granitic and gneissic basement) regions of India. this new electrical tomography (imaging) technique provided detailed 'pictures' of the subsurface that showed variation in bedrock topography and the nature and thickness of the overburden. The resulting images were used to plan borehole investigations more cost effectively (Barker et al., 2001; Agbemuko et al., 2017).

Groundwater is not difficult to find in Zaria as the water table is generally within a few metres of the ground surface. Here, groundwater is not only used to provide water for public supply, but also for irrigation. However, the yield of boreholes is frequently low and supplies do not have long term sustainability.
Therefore, to site successful boreholes to tap groundwater in hard rock areas like Zaria is a complex problem due to the heterogeneous nature of the aquifer system and so the hydrogeology of the subsurface needs first to be investigated in considerable detail.

The aim of this survey is the Application of 2D geoelectrical resistivity imaging for groundwater development. The objectives of the survey were to determine the thickness of the overburden and the weathered basement, to resolve the overburden layering, geometry of acquirers, salinity of the groundwater and to evaluate the groundwater potential of the area; thus characterizing the geologic setting at the surveyed area.

\section{MATERIALS AND METHODS}

Description of Study Area: The Ahmadu Bello University Teaching Hospital (ABUTH) is located along Zaria-Funtua road, Shika, Zaria. The geology is that of the crystalline metamorphic rocks of the northern Nigerian Basement Complex (Wright and McCury, 1970). The ABUTH lies between latitudes 
$11^{\circ} 7^{\prime} \mathrm{N}$ and $11^{\circ} 24^{\prime} \mathrm{N}$ and longitudes $7^{\circ} 31^{\prime} \mathrm{E}$ and $7^{\circ}$ $50^{\prime} \mathrm{E}$ and has an elevation of about $650 \mathrm{~m}-700 \mathrm{~m}$ above mean sea level. Ahmadu Bello University Teaching Hospital (ABUTH) is located in Shika, along Zaria-Funtua road north of Ahmadu Bello University main campus, Samaru. It lies between latitudes $11.18^{\circ} \mathrm{N}$ and $11.17^{\circ} \mathrm{N}$ and longitudes $07.60^{\circ}$ $\mathrm{E}$ and $07.61^{\circ} \mathrm{E}$. It is bordered by Zaria Academy in the north, Bomo village in the northeast, Area C A.B.U. staff quarters, Institute for Agricultural Research (IAR) farm and its dam. Accessibility of the ABUTH is only by the Zaria-Funtua road which is a prominent federal road. All season motorable roads, some of which are tarred exist within the premises. Rainfall is the dominant factor that determines the occurrence of groundwater in the survey area. As such, this factor greatly affects the groundwater in the Shika. During the rainy season, Shika and its catchment area enjoy a fairly high amount of rainfall. Rainfall data for the last forty years show that the highest rainfall occurs in August while the lowest is in November. The average annual rainfall is about $1092 \mathrm{~mm}$ (Olufemi, 1985). The criteria that make formation a good aquifer include high effective porosity and permeability. These in turn depend on the degree of weathering and fracturing of the rocks.

Methodology: Geophysics is one of the methods we can increase the efficiency and effectiveness of borehole siting investigations, with resistivity sounding being the most widely employed technique. A modern and state-of-the-art field instrument, the ABEM Automatic LUND Imaging System (Terrameter SAS 4000 and ES 464), produced by ABEM instrument $\mathrm{AB}$, was used to accomplish this task. This uses multi-core cables with takeouts at $5 \mathrm{~m}$ intervals, having a total of 42 electrodes covering a spread of $200 \mathrm{~m}$. A Wenner CVES array with protocol, WEN32SX was used to map the geoelectrical properties as an aid to characterizing the ground conditions. In the present survey, a $5 \mathrm{~m}$ interval between 41 electrodes was employed with each spread having a length of $200 \mathrm{~m}$. Three profiles were covered.

\section{RESULTS AND DISCUSSIONS}

The data were processed to display the variations of electrical resistivities using the RES2DINV software. The electrical images along the profiles and their interpretation are discussed in this section. A total of six profiles were taken but only three profiles were used for this survey, because of the objectives of the study. One of them, profile 4 is north-south trending while profiles 5 and 6 are west-east trending. Profiles 5 and 6 are also parallel with profile 4 perpendicular to them. The results show three distinct images for each profile. The upper image labelled (a) is a plot of the measured apparent resistivity pseudosection. The middle image labelled (b) is the calculated apparent resistivity pseudosection and the lower image labeled (c) is the true resistivity model obtained after a definite number of iterations of the inversion program. A borehole is also superimposed on the inverse model for easy correlation.

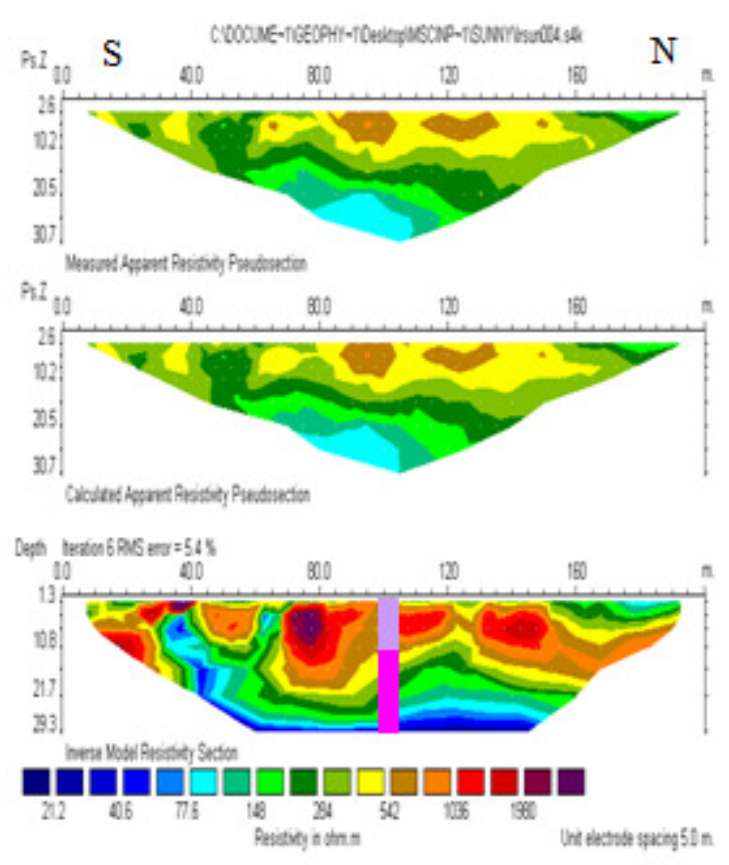

Fig 1. The result of 2D inversion of the Wenner-array data along Survey line 4, in the ABUTH residential quarters

Figure 1 shows resistivity inversion results (iteration 6, $5.4 \%$ total average RMS error), for profile 4 . Thus indicating that good fits between the measured (observed) and calculated apparent resistivity data were achieved. A thin layer of resistivity anomaly $(<148 \Omega \mathrm{m}->542 \Omega \mathrm{m})$ on the top indicates the presence of surface water in silt, sand and clay. Gravel and sand and consolidated laterite $(<542 \Omega \mathrm{m}->1036$ $\Omega \mathrm{m}$ ) is also seen at the surface to a depth of over $16 \mathrm{~m}$ below the surface. Gravel and sand is sandwiched by consolidated laterite. The weathered basement continues from this depth to the fresh basement. The weathered basement shows variable resistivity $(<148$ $\Omega \mathrm{m}-542 \Omega \mathrm{m}$ ) signifying fractured crystalline rock which has weathered into clay, sand and gravel constituting the aquifer. Also a very low resistivity zone $(<21.2 \Omega \mathrm{m}->77.6 \Omega \mathrm{m})$ is seen in this layer. This is a fracture zone in the bedrock believed to hold water. The increased thickness of weathering here provides a good reservoir with a higher probability of bedrock fracturing. The fresh crystalline basement is not revealed in this image, so it is likely at a depth greater than $30 \mathrm{~m}$. Patches of unweathered bedrock 
( $>1980 \Omega \mathrm{m}$ ) is observed close to the surface below the $40 \mathrm{~m}$ and $80 \mathrm{~m}$ marks. This pseudosection correlated well with the borehole logs obtained from the Preussag Ltd and ABUTH hostels.

Figure 2 shows resistivity inversion results (iteration $6,3.6 \%$ total average RMS error), for profile 5. Thus indicating that good fits between the measured (observed) and calculated apparent resistivity data were achieved. A high resistivity anomaly $(<78.1 \Omega \mathrm{m}$ - $>755 \Omega \mathrm{m}$ ) is seen in the top of the image and constitutes the overburden, having a thickness of about $15 \mathrm{~m}$. This layer is made up of silt, clay, sand, and brownish consolidated laterite.

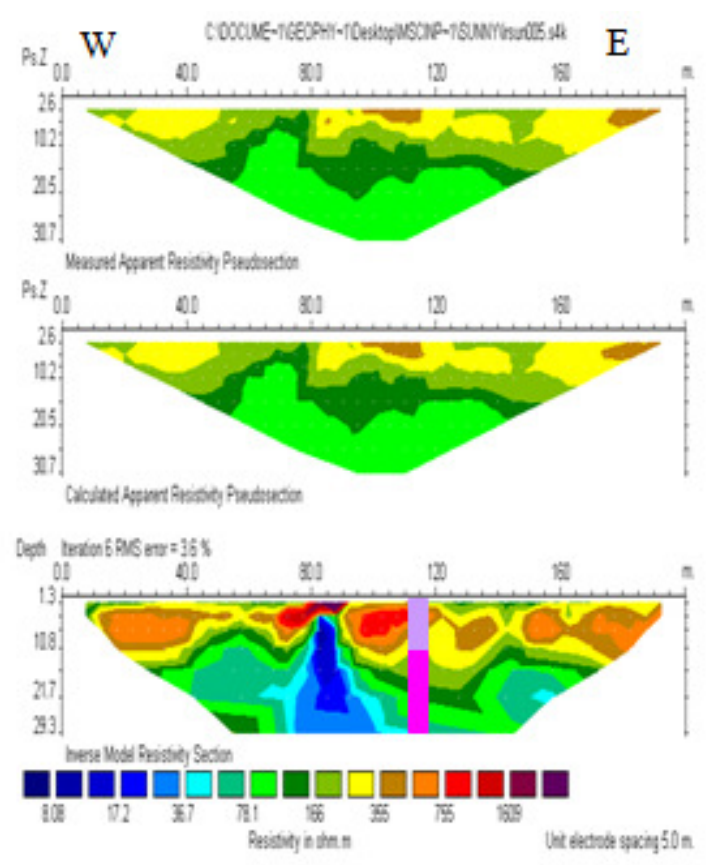

Fig 2. The result of $2 \mathrm{D}$ inversion of the Wenner-array data along survey line 5, in the ABUTH residential quarters

There was probably a filling of laterite some time ago. A thick weathered basement $(<78.1 \Omega \mathrm{m}->355 \Omega \mathrm{m})$ composed of gravel, sand and clay grades into the fresh basement at a depth greater than $30 \mathrm{~m}$. This is the aquiferous layer. The increased thickness of weathering here provides a good reservoir with a higher probability of bedrock fracturing. Hence, there is a narrow vertical low resistivity zone $(<8.08 \Omega \mathrm{m}-$ $>36.7 \Omega \mathrm{m}$ ) with a width of less than $10 \mathrm{~m}$ (but increases downwards) below the $85 \mathrm{~m}$ mark, which is probably a fracture zone in the bedrock trapping groundwater in the aquifer streaming to the surface. This position would be the best location to site a borehole in the area. The depth to the fresh crystalline basement is greater than $30 \mathrm{~m}$. This pseudosection correlated well with the borehole logs obtained from the Preussag Ltd and ABUTH hostels. Figure 3 shows resistivity inversion results (iteration $7,5.8 \%$ total average RMS error), for profile 6 . Thus indicating that good fits between the measured (observed) and calculated apparent resistivity data were achieved. The image shows a large thickness of weathered rock covering the crystalline bedrock. The overburden is composed of gravel, sand, clay and silts $(<260 \Omega \mathrm{m}$ $>1759 \Omega \mathrm{m})$, consolidated laterite. Unweathered bedrock material $(<1759 \Omega \mathrm{m}->4578 \Omega \mathrm{m})$, is also seen as part of a road traversed by the profile at the 105 $\mathrm{m}-120 \mathrm{~m}$ marks. Other isolated patches of laterite traversed by the profile are seen at the $95 \mathrm{~m}, 140 \mathrm{~m}$ and $155 \mathrm{~m}$ marks.

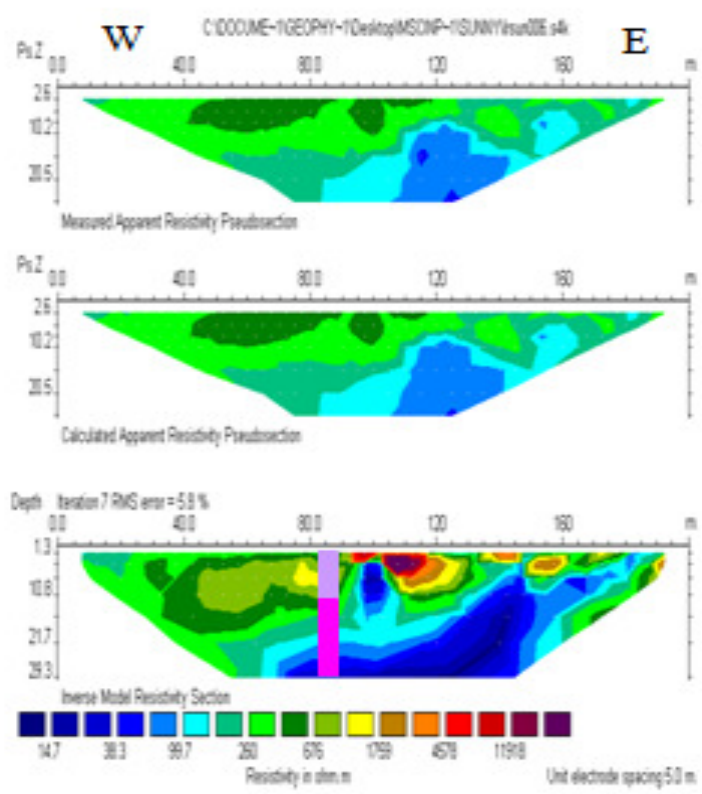

Fig 3. The result of $2 \mathrm{D}$ inversion of the Wenner-array data along survey line 6, in the ABUTH residential quarters

The weathered basement contains a low resistivity zone $(<14.7 \Omega \mathrm{m}->99.7 \Omega \mathrm{m})$ as seen rising to the surface at the $100 \mathrm{~m}$ and $185 \mathrm{~m}$ marks. This is probably a fracture zone containing water. This weathered basement grades into the fresh crystalline basement. There is a prominent high resistivity anomaly $>11918$ $\Omega \mathrm{m}$, near the centre of the pseudosection. This is seen near the surface at the $110 \mathrm{~m}$ mark and this is possibly a cave or cavity.

The inversion model gives the depth to the top of the cave at around $5 \mathrm{~m}$. However, the degree of weathering is appreciably good and the increased thickness of weathering here provides a good reservoir that enhances bedrock fracturing. The depth to the fresh basement is greater than $30 \mathrm{~m}$, so it is not 
revealed by the image. This pseudosection correlated well with the borehole logs obtained from Messrs Preussag Ltd and ABUTH hostels.

Conclusions: The results of this survey in correlation with borehole data revealed three distinct layers: firstly, the overburden which is about $16 \mathrm{~m}-26 \mathrm{~m}$ thick having a resistivity range of about $194 \Omega \mathrm{m}-$ $1759 \Omega \mathrm{m}$. In some places the overburden consists of top brownish red lateritic clay, about $9 \mathrm{~m}$ thick underlain by a brownish sandy clay soil, about $7 \mathrm{~m}$ thick. Hydrogeologically, the weathered overburden has a high porosity and contains a significant amount of water. Secondly, the weathered basement which is appreciably thick (about $5 \mathrm{~m}-14 \mathrm{~m}$ ), is highly fractured and weathered, so constitutes a good aquifer having a resistivity range of about $0.687 \Omega \mathrm{m}-678$ $\Omega \mathrm{m}$.

The weathered basement is composed of schistose rock materials, gravel and sand. The thickness is variable, as confirmed by the NWRI, 1 and 2, (2002). Thirdly, the bedrock on the other hand is fresh but frequently fractured and weathered which gives it a high permeability. The fresh crystalline basement mostly granite and schist has a resistivity of about $1223 \Omega \mathrm{m}$. The fresh crystalline basement rock is at a variable depth of about $21 \mathrm{~m}-40 \mathrm{~m}$ below the surface. But as fractures do not constitute a significant volume of the rock, fractured basement has a low porosity. For this reason a good borehole providing long term high yield would be one which penetrates a large thickness of regolith, which acts as a reservoir, and also intersects fractures in the underlying bedrock, the fractures providing the rapid transport mechanism from the reservoir and hence the high yield.

Acknowledgements: The authors sincerely thank Prof. I. B. Osazuwa, Prof. Nasiru Rabiu, Ahmed Sadiq, Prof. K. M. Lawal, Joseph Osumeje, Bolaji T. Lawal, El-Khalil, postgraduate students of 2007/2008 session and the staff of the Department of Physics, A. B. U., Zaria, for their invaluable contributions and support that has made this work a dream come true.

\section{REFERENCES}

Agbemukop, OS; Tamunobereton-Ari, I; Ngah, SA (2017). Determination of the effects of dumpsites on aquifer at Port Harcourt metropolis Rivers State, Nigeria. IOSR Journal of applied physics. 9(6), 41 -54 .

Barker, R. D. 2001. Imaging fractures in hardrock terrain. Research Note 2. University of Birmingham, UK. 1 - 4.

Barker, R; Venkateswararao, T; Thangarajan, M (2001). Electrical imaging for borehole siting in India. Research Note 3. University of Birmingham, UK. $1-7$.

National Water Resources Institute (NWRI, 1). 2002. Groundwater Research Development. Completion Report. Borehole NR. GWR/HG-05(1/6).

National Water Resources Institute (NWRI, 2). 2(002). Groundwater Research Development. Completion Report. Borehole NR. HGD/IAR/01(1/6).

Olufemi, R O (1985). Hydrogeology of Jama'a Kubanni Area. (Zaria Sheet 102 SW). Unpublished B. Sc. Thesis. Department of Geology, Ahmadu Bello University, Zaria

Umar, FA (2001). Geoelectric investigation of the groundwater potential in the Institute of Agricultural Research (IAR) farm, Samaru, Zaria. Unpublished M.Sc. thesis. Department of Physics, Ahmadu Bello University, Zaria.

Wright, J.B. and McCury, P. 1970. The geology of Nigeria Sheet 102 SW, Zaria and its regions. Edited by M.J. Mooretimore. Department of Geography, Occasional Paper 4, Ahmadu Bello University, Zaria. 